\title{
Mucosal Protective Effect of Leminoprazole on Reflux Esophagitis Induced in Rats
}

\author{
Susumu Okabe, Yusuke Takinami, Kazumi Iwata and Tsukimi Yanagawa \\ Department of Applied Pharmacology, Kyoto Pharmaceutical University, Misasagi, Yamashina, Kyoto 607, Japan
}

Received July 6, 1995 Accepted September 11, 1995

\begin{abstract}
We examined the effect of leminoprazole (an acid pump inhibitor) on reflux esophagitis induced in rats. Intragastrically administered leminoprazole significantly and dose-dependently protected the esophageal mucosa against the reflux of gastric contents, without affecting gastric acid secretion. However, it had no effect on the esophagitis when administered intraduodenally, despite its significant inhibition (about $40 \%$ ) of gastric acid secretion. Omeprazole significantly prevented the development of esophagitis, most probably through potent inhibition of gastric acid secretion. Indomethacin significantly reduced the synthesis of prostaglandin $E_{2}$ in the esophagus. Since indomethacin pretreatment had no effect on the esophageal protection by leminoprazole, omeprazole or sucralfate, the involvement of endogenous prostaglandins can be ruled out as a possible underlying mechanism. Intragastrically, but not intraduodenally, administered sucralfate significantly prevented the esophagitis even at a dose not affecting gastric acid secretion. These results strongly suggest that both leminoprazole and sucralfate protect the esophageal mucosa directly.
\end{abstract}

Keywords: Leminoprazole, Omeprazole, Sucralfate, Reflux esophagitis

There is increasing evidence that gastric acid pump inhibitors exert a much more favorable effect on reflux esophagitis than $\mathrm{H}_{2}$-blockers through their profound and long-lasting antisecretory activities $(1-3)$. Even in animal experiments, both omeprazole and lansoprazole provided marked protection of the esophageal mucosa against the reflux of gastric contents $(4,5)$. We developed a new gastric acid pump inhibitor, leminoprazole (NC-1300-O-3), that has antisecretory, mucosal protective and ulcer healing effects in rats $(6-9)$. The present study was performed to determine if leminoprazole protects the esophageal mucosa against the reflux of gastric juice. Omeprazole and sucralfate were used as reference drugs.

\section{MATERIALS AND METHODS}

\section{Animals}

Eight-week-old male Sprague-Dawley rats (CharlesRiver Japan, Kanagawa), weighing 250-270 g, were fasted for $18 \mathrm{hr}$. Drinking water was freely available to the animals up to $2 \mathrm{hr}$ before the experiments. All animals were kept in raised mesh-bottom cages to prevent coprophagy. Four to ten rats were included in each group.

\section{Esophagitis induction}

Under ether anesthesia, the abdomen was incised along the midline and then both the pylorus and limiting ridge (transitional region between the forestomach and corpus) were simultaneously ligated according to the method described by Nakamura et al. (10). Consequently, the total capacity of the stomach to preserve the gastric juice was greatly diminished, resulting in the reflux of gastric juice into the esophagus. Two, 3, 4 or $6 \mathrm{hr}$ later, the animals were killed with an overdose of ether, and then the esophagus and stomach were removed as a single unit. The total area $\left(\mathrm{mm}^{2}\right)$ of lesions that had developed in the esophagus was determined under a dissecting microscope $(\times 10)$ and graded as follows: 0 , no visible lesions; 1 , a few erosions; 2 , total area of lesions $\leqq 30 \mathrm{~mm}^{2} ; 3$, total area of lesions $\geqq 31 \mathrm{~mm}^{2} ; 4$, perforation. The test drugs were administered either intragastrically (i.g.) by gastric intubation or intraduodenally (i.d.) immediately after ligation of the pylorus and limiting ridge. To determine whether or not endogenous prostaglandins are involved in the protective mechanism of drugs, indomethacin (5 $\mathrm{mg} / \mathrm{kg}$ ) was pretreated subcutaneously (s.c.) $1 \mathrm{hr}$ before ligation of the pylorus and limiting ridge. 


\section{Gastric secretory study}

It was rational to examine the effects of drugs using a preparation involving the ligation of the pylorus and limiting ridge. However, there is often leakage of gastric contents from the mouth nearly $2 \mathrm{hr}$ after ligation of these portions. Therefore, we used a preparation with only the pylorus ligated. The abdomen was incised under ether anesthesia and only the pylorus was ligated. Four hours later, the animals were killed with an overdose of ether. The gastric contents were collected and its volume $(\mathrm{ml} / \mathrm{rat})$ and acidity $(\mathrm{mEq} / \mathrm{l})$ were determined. Total acidity was determined by automatic titration of the gastric juice against $0.1 \mathrm{~N} \mathrm{NaOH}$ to $\mathrm{pH} 7.0$ (Comtite 5; Hiranuma, Tokyo). Acid output was expressed as $\mu \mathrm{Eq}$ $/$ hr. In the case of sucralfate administered i.g., only the volume and $\mathrm{pH}$ of the contents were determined, acidity not being determined because sucralfate itself consumes $\mathrm{NaOH}$ to some extent. The test drugs were administered at $3-300 \mathrm{mg} / \mathrm{kg}$, i.g. or i.d. immediately after pylorus ligation. The volume of the drug or vehicle was $0.5 \mathrm{ml} / 200$ $\mathrm{g}$ or $1.0 \mathrm{ml} / 200 \mathrm{~g}$ of body weight for i.g. or i.d. treatment, respectively.

\section{Determination of prostaglandin $E_{2}$}

Synthesis of prostaglandins $E_{2}$ in the esophagus was determined by the method of Lee and Feldman $(11,12)$. Briefly, under ether anesthesia, the esophagus was isolated, weighed and placed in a vial that contained $1 \mathrm{ml}$ of Tris buffer ( $50 \mathrm{mmol} / \mathrm{l}, \mathrm{pH} 8.4)$ and was kept cool on ice. The specimen was minced for about $15 \mathrm{sec}$ with scissors, washed and centrifuged at $9,000 \times g$ for $15 \mathrm{sec}$. The supernatant was discarded and an additional $1 \mathrm{ml}$ of Tris buffer was added to the vial. Each sample was mixed with a vortex mixer for $60 \mathrm{sec}$ at $25^{\circ} \mathrm{C}$ and then centrifuged again at $9,000 \times g$ for $15 \mathrm{sec}$. The supernatants were stored at $-80^{\circ} \mathrm{C}$, and then prostaglandin $\mathrm{E}_{2}$ generated was determined by an enzyme immunoassay kit (Cayman Chemical, Ann Arbor, MI, USA). Prostaglandin $\mathrm{E}_{2}$ was expressed as $\mathrm{pg} / \mathrm{mg}$ tissue/min. Esophageal samples were obtained immediately before and $0.5 \mathrm{hr}$ or $4 \mathrm{hr}$ after indomethacin treatment $(5 \mathrm{mg} / \mathrm{kg}$, s.c. $)$.

\section{Drugs}

Leminoprazole and omeprazole (provided by Nippon Chemiphar, Tokyo) were suspended in $0.5 \%$ carboxymethylcellulose. Sucralfate (Chugai, Tokyo) was suspended in distilled water. Indomethacin (Sigma, St. Louis, MO, USA) was suspended in a small amount of Tween 80 (Wako, Osaka) and $0.5 \%$ carboxymethylcellulose.

\section{Statistical analysis}

Statistical analysis was performed by the Kruskal-
Wallis rank test and two-tailed Dunnett's multiple comparison test, values of $\mathrm{P}<0.05$ being regarded as significant. $\mathrm{ED}_{50}$ values and confidence limits were calculated from the dose-inhibition relationships by the least squares method.

\section{RESULTS}

\section{Effects of test drugs on reflux esophagitis}

With the surgical procedure used in this study, reflux esophagitis developed in the thoracic esophagus in 7 of 8 animals $3 \mathrm{hr}$ after ligation (Fig. 1). However, both the severity and incidence of esophagitis were increased when each esophagus was examined $4 \mathrm{hr}$ later. The incidence of perforation was about $50 \%$. Nearly the same result was obtained at $6 \mathrm{hr}$ after ligation, so we selected $4 \mathrm{hr}$ as the experimental time. Both leminoprazole ( 30 or $60 \mathrm{mg} / \mathrm{kg}$ ) and omeprazole $(60 \mathrm{mg} / \mathrm{kg})$ administered i.g. significantly prevented the development of esophagitis (Fig. 2). The $\mathrm{ED}_{50}$ values of these drugs were $12.7 \mathrm{mg} / \mathrm{kg}(8.0-19.2)$ and $25.9 \mathrm{mg} / \mathrm{kg}(20.4-32.8)$, respectively. Sucralfate (10, 30,100 or $300 \mathrm{mg} / \mathrm{kg}$ ) administered i.g. also significantly prevented esophagitis. Neither leminoprazole $(10,30$ or $60 \mathrm{mg} / \mathrm{kg}$ ) nor sucralfate $(100$ or $300 \mathrm{mg} / \mathrm{kg}$ ) administered i.d. prevented the development of esophagitis (Fig. 3). In contrast, omeprazole (30 or $60 \mathrm{mg} / \mathrm{kg}$ ) administered i.d. significantly prevented it. The $E D_{50}$ value was $5.9 \mathrm{mg} / \mathrm{kg}(2.6-9.4)$. Pretreatment with indomethacin had no influence on the protective effect of leminoprazole (60 mg/kg, p.o.), omeprazole $(60 \mathrm{mg} / \mathrm{kg}$, p.o.) or sucralfate $(300 \mathrm{mg} / \mathrm{kg}$ ) (Fig. 4).

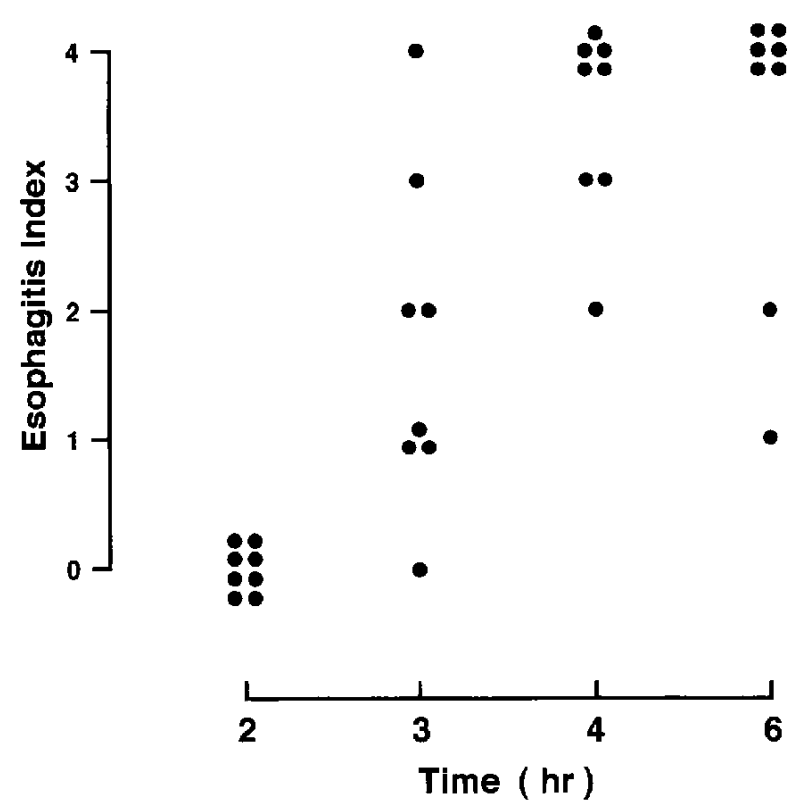

Fig. 1. Time course of reflux esophagitis induced in rats. 

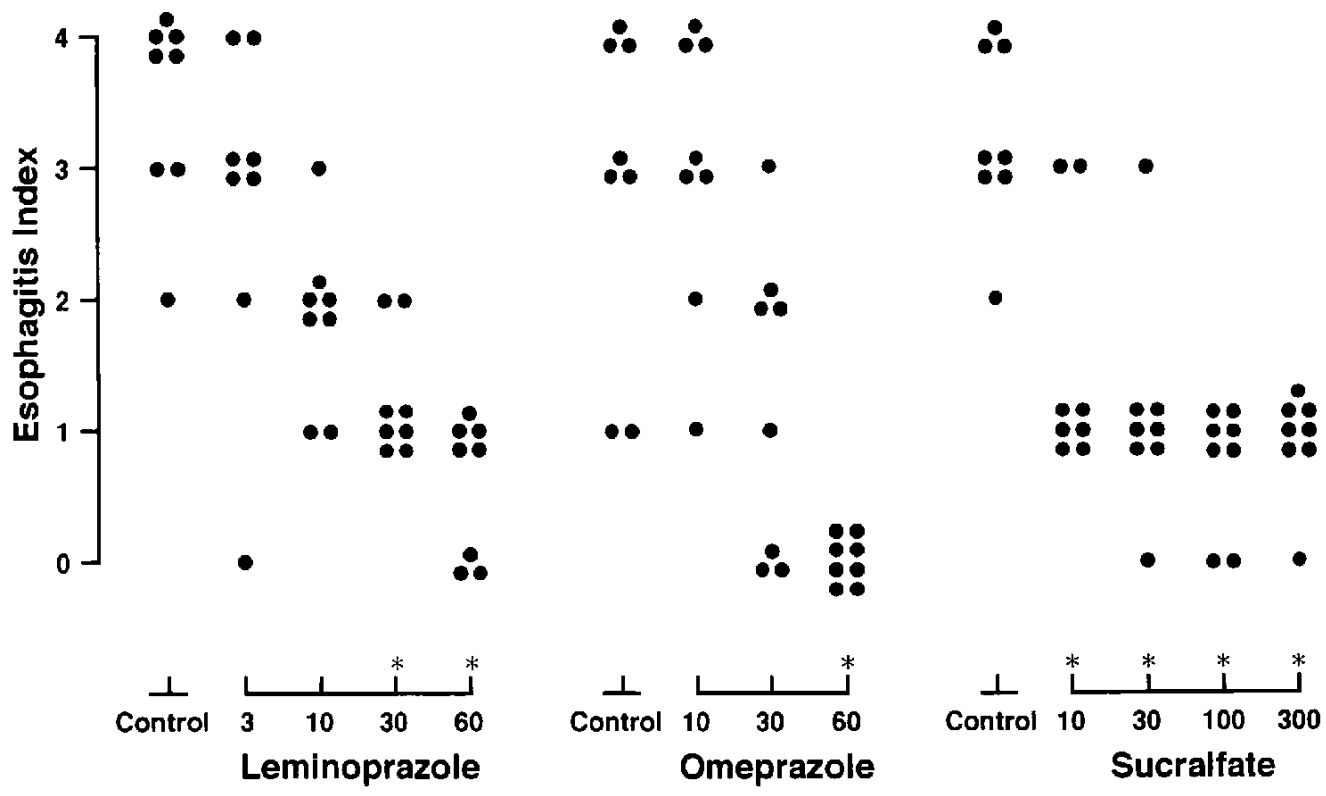

Fig. 2. Effects of leminoprazole, omeprazole and sucralfate on reflux esophagitis induced in rats. The drugs were administered intragastrically (i.g.) 5 min after simultaneous ligation of the pylorus and limiting ridge. *Significantly different from the control values, at $\mathrm{P}<0.05$.

\section{Effects of test drugs on gastric secretion}

Leminoprazole ( 3 and $10 \mathrm{mg} / \mathrm{kg}$ ) administered i.g. had little or no effect on gastric acid output (Fig. 5). At 30 and $60 \mathrm{mg} / \mathrm{kg}$, however, it significantly increased the volume of the gastric contents $(11.2 \pm 0.6 \mathrm{ml} / \mathrm{rat}$ and $11.9 \pm 0.7$ $\mathrm{ml} /$ rat vs $7.2 \pm 0.9 \mathrm{ml} / \mathrm{rat}$ in the controls), without any effect on the acid output. Omeprazole $(10 \mathrm{mg} / \mathrm{kg}) \mathrm{ad}-$ ministered i.g. significantly inhibited the acid output by $40.9 \%$. At 30 or $60 \mathrm{mg} / \mathrm{kg}$, it caused a significant reduction in the acid output; the inhibition of acid output amounted to $59.8 \%$ and $63.1 \%$, respectively. The volume of the gastric contents significantly or insignificantly

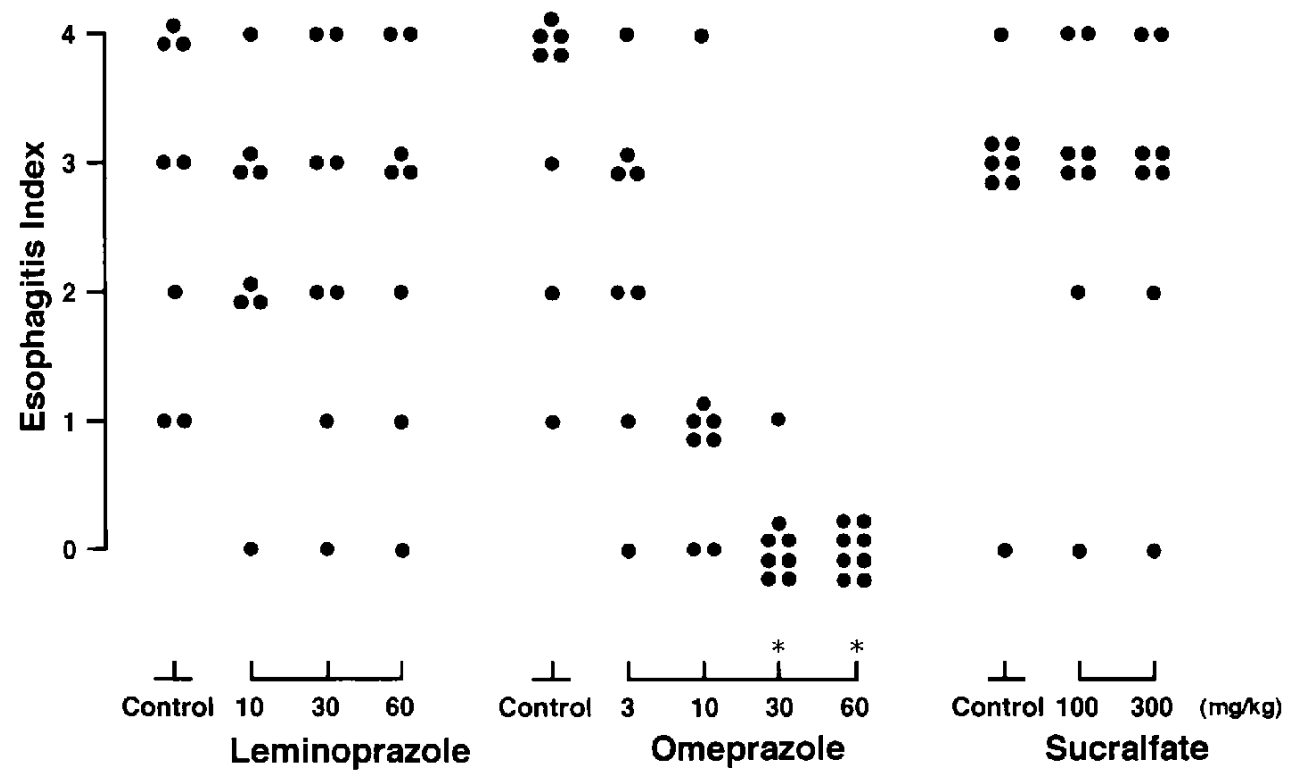

Fig. 3. Effects of leminoprazole, omeprazole and sucralfate on reflux esophagitis induced in rats. The drugs were administered intraduodenally (i.d.) immediately after simultaneous ligation of the pylorus and limiting ridge. *Significantly different from the control values, at $\mathrm{P}<0.05$. 


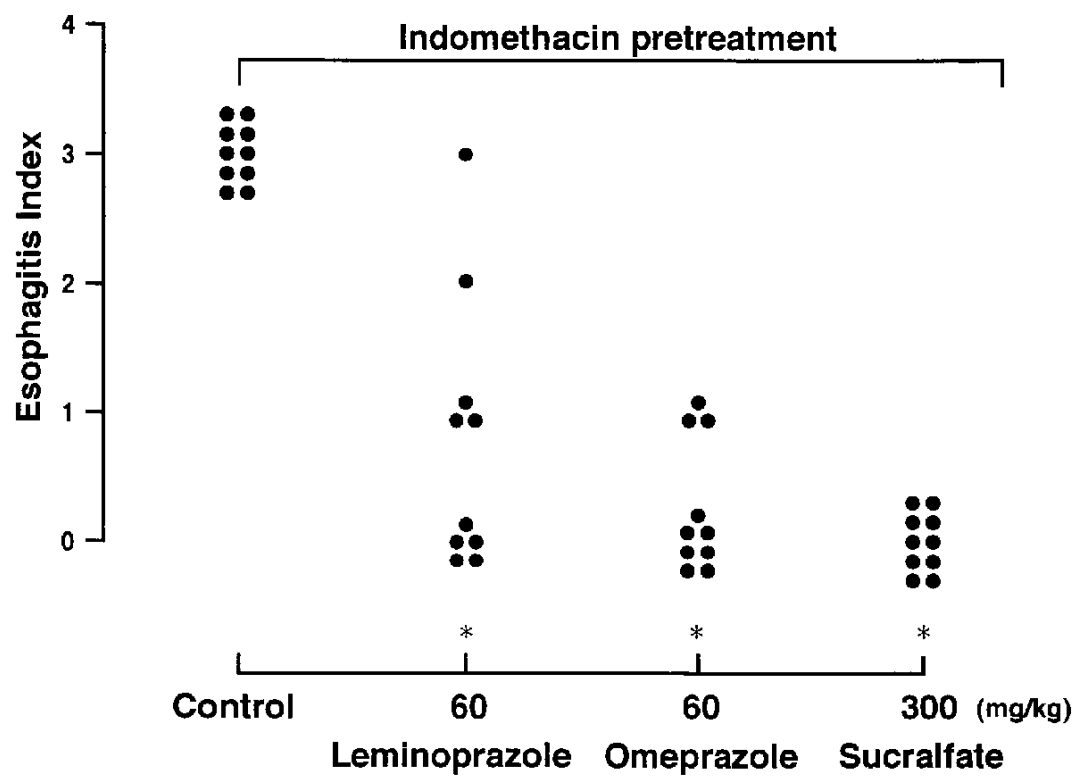

Fig. 4. Effect of pretreatment with indomethacin on the protective effects of leminoprazole, omeprazole and sucralfate on reflux esophagitis induced in rats. Indomethacin $(5 \mathrm{mg} / \mathrm{kg}$ ) was administered subcutaneously (s.c.) $1 \mathrm{hr}$ before ligation of the pylorus and limiting ridge. The drugs were administered $5 \mathrm{~min}$ after ligation. *Significantly different from the control values, at $\mathbf{P}<0.05$.

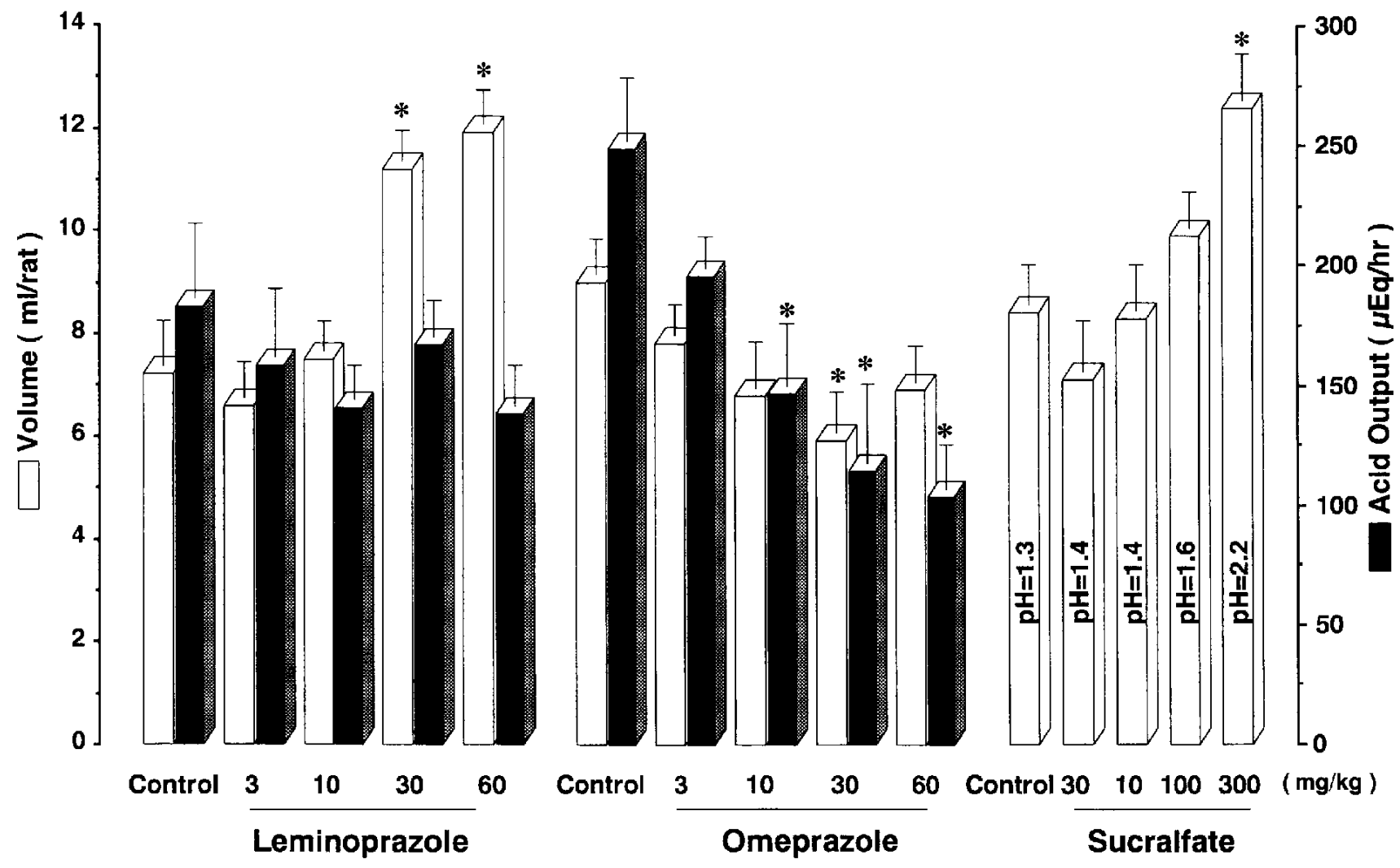

Fig. 5. Effects of leminoprazole, omeprazole and sucralfate on gastric acid secretion in pylorus-ligated rats (4 hr). The drugs were administered intragastrically (i.g.) 5 min after pylorus ligation. Values are means \pm 1 S.E.M. for 8 rats. ${ }^{*}$ Significantly different from the control values, at $\mathrm{P}<0.05$. 

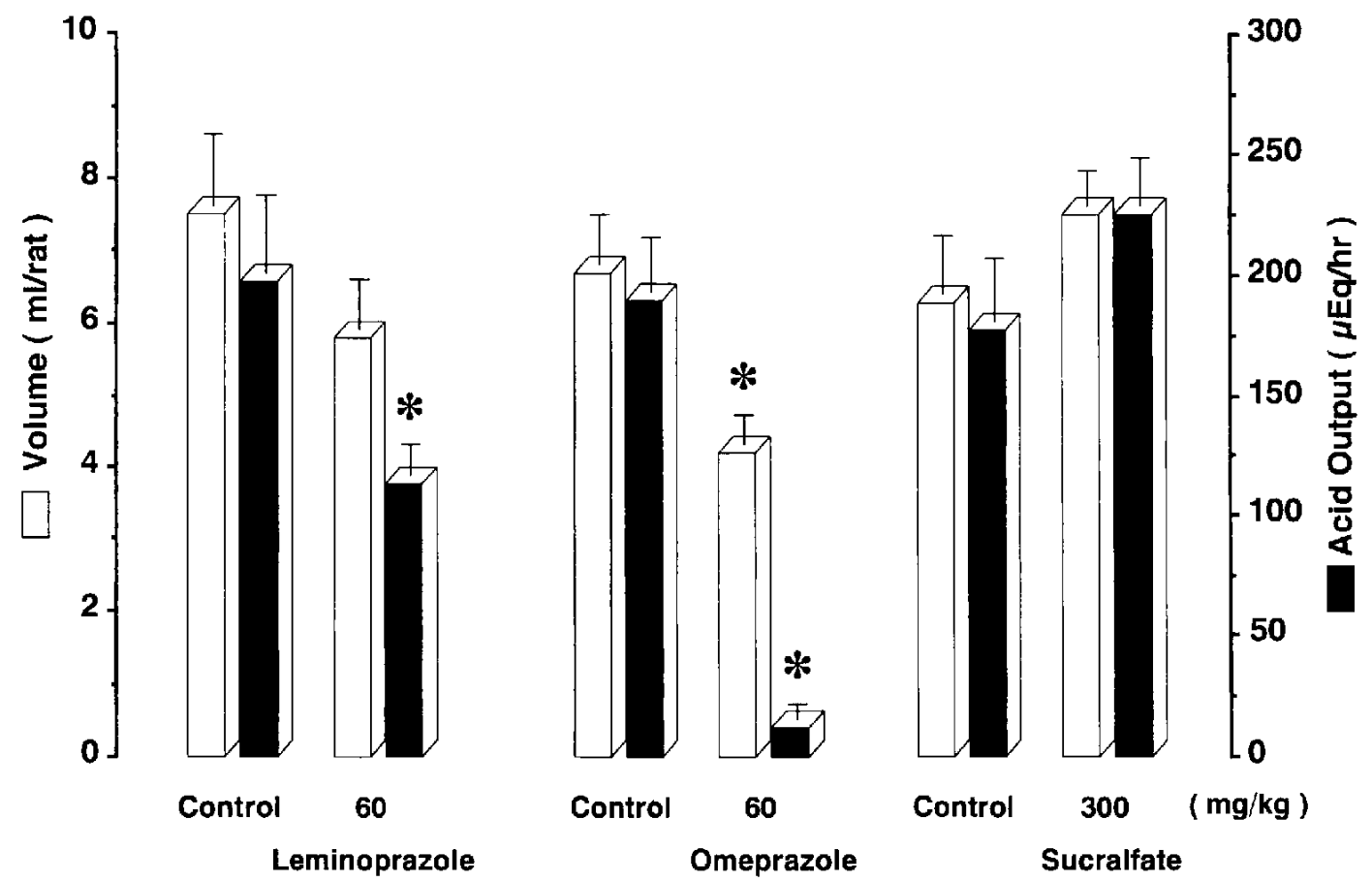

Fig. 6. Effects of leminoprazole, omeprazole and sucralfate on gastric secretion in pylorus-ligated rats (4hr). The drugs were administered intraduodenally (i.d.) immediately after pylorus ligation. Values are means \pm 1 S.E.M. for 8 rats. ${ }^{*}$ Significantly different from the control values, at $\mathrm{P}<0.05$.

decreased with these doses, i.e., by about $20 \%$. Sucralfate $(10,30$ or $100 \mathrm{mg} / \mathrm{kg})$ administered i.g. had little or no effect on the $\mathrm{pH}$ of the gastric contents. At $300 \mathrm{mg} / \mathrm{kg}$, it caused a significant increase in the volume of the gastric contents $(12.0 \mathrm{ml} \mathrm{vs} 8.0 \mathrm{ml}$ in the controls). The $\mathrm{pH}$ of the contents was also increased to 2.2 vs 1.3 in the controls. When administered i.d., however, both leminoprazole ( 60 $\mathrm{mg} / \mathrm{kg})$ and omeprazole $(60 \mathrm{mg} / \mathrm{kg})$ significantly inhibited the acid output by $42.4 \%$ and $93.6 \%$, respectively (Fig. 6). The volume of the gastric contents was significantly reduced by omeprazole, but tended to be decreased by leminoprazole. Sucralfate $(300 \mathrm{mg} / \mathrm{kg}$, i.d.) slightly increased the volume of the gastric contents and acid output compared with the control values. The $\mathrm{pH}$

Table 1. Effect of indomethacin pretreatment on prostaglandin $\mathrm{E}_{2}$ synthesis in the rat esophagus

\begin{tabular}{lcc}
\hline & $\begin{array}{c}\text { Prostaglandin } \mathrm{E}_{2} \text { synthesis } \\
(\mathrm{pg} / \mathrm{mg} \text { tissue/min })\end{array}$ & Inhibition (\%) \\
\hline Contol & $9.42 \pm 2.85$ & - \\
$0.5 \mathrm{hr}$ & $2.89 \pm 1.49$ & 69.3 \\
$4 \mathrm{hr}$ & $1.39 \pm 0.69^{*}$ & 85.2 \\
\hline
\end{tabular}

Prostaglandin synthesis was determined $0.5 \mathrm{hr}$ and $4 \mathrm{hr}$ after indomethacin $(5 \mathrm{mg} / \mathrm{kg}$, subcutaneously) treatment. Data are means \pm S.E.M. for 4 rats. *Significantly different from the control values, at $\mathrm{P}<0.05$. was 1.4 in both the sucralfate-treated and control groups.

\section{Effect of indomethacin on prostaglandin $E_{2}$ synthesis}

The prostaglandin $\mathrm{E}_{2}$ synthesis in the normal esophagus was $9.42 \pm 2.85 \mathrm{pg} / \mathrm{mg}$ tissue $/ \mathrm{min}$. The synthesis was markedly reduced at $0.5 \mathrm{hr}$ and $4 \mathrm{hr}$ after indomethacin treatment by $69.3 \%$ and $85.2 \%$, respectively (Table 1 ). The inhibition observed at $4 \mathrm{hr}$ was statistically significant.

\section{DISCUSSION}

The results indicate that leminoprazole, omeprazole and sucralfate markedly protect the esophageal mucosa from the reflux of gastric juice, depending on the route of administration. Therefore, the underlying mechanisms seem to be different from each other. First, the mechanism of action of i.g. administered leminoprazole appears to be unrelated to the gastric secretory conditions because gastric acid secretion was not inhibited with that route. Rather, the volume of the gastric juice increased with the drug. This increased volume with leminoprazole was observed in our previous studies, although at that time it was administered orally for 4 weeks (7). The mechanism underlying this increase in the volume remains unknown. In our preliminary study, increased permeability of the gastric mucosa, as judged from the Evans blue, was ob- 
served after i.g. administration of the drug. As shown in this study, the i.d. administration of leminoprazole at 60 $\mathrm{mg} / \mathrm{kg}$ tended to decrease the volume of the gastric juice. Therefore, the increase in the volume of the gastric juice after i.g. administration appears to be due to direct irritation of the gastric mucosa by leminoprazole. There is a possibility that the protective action of leminoprazole is due to the dilution of gastric contents since the gastric juice volume was significantly increased at 30 and 60 $\mathrm{mg} / \mathrm{kg}$. The degree of the increase in the volume was quite similar at these doses. However, the development of esophagitis was not significantly inhibited by $30 \mathrm{mg} / \mathrm{kg}$ of the drug. Therefore, the mechanism of action of leminoprazole would not be simply due to the dilution of gastric juice, but due to a specific protective effect. It was found that the gastric acid output was reduced by about $40 \%$ when leminoprazole was administered i.d. at 60 $\mathrm{mg} / \mathrm{kg}$. Of note was that even at $60 \mathrm{mg} / \mathrm{kg}$, leminoprazole had little or no effect on esophagitis. This result strongly suggests that about $40 \%$ of acid inhibition is not enough to prevent the development of esophagitis. Once again, this finding rules out the possible participation of gastric acid in the mechanism underlying the protective activity of the i.g. administered drug. Leminoprazole has a cytoprotective effect against necrotizing agent-induced gastric lesions (6). Therefore, it is likely that this protection of the esophagus and the stomach might involve the same mechanism.

Similar to leminoprazole, omeprazole extensively prevented the development of esophagitis on i.g. administration, as reported by Goto and Kishi (5). It significantly inhibited the gastric acid output by about $60 \%$ when administered p.o. at 30 or $60 \mathrm{mg} / \mathrm{kg}$. Since the pylorus was ligated, the antisecretory effect of omeprazole might mainly comprise its direct effect on parietal cells and partly, if any, that of the absorbed drug. Thus, it is possible that the protective effect of omeprazole is partly due to this antisecretory effect. Although the degree of inhibition of acid is nearly the same with 30 and 60 $\mathrm{mg} / \mathrm{kg}$, the protection observed with $30 \mathrm{mg} / \mathrm{kg}$ was insignificant. Therefore, the protection by $60 \mathrm{mg} / \mathrm{kg}$ may be partly related to the mucosal protection, which is identical to the gastric protection by this drug $(13,14)$. In contrast to leminoprazole, omeprazole administered i.d. markedly protected the esophagus from the reflux of gastric contents. The dose that inhibited esophagitis is one that inhibits gastric secretion by more than $90 \%$. Therefore, this protection might be purely caused by the inhibition of acid secretion.

Sucralfate is known to be quite effective for the treatment of human reflux esophagitis $(15,16)$. As expected, sucralfate administered i.g. markedly prevented the development of experimentally-induced esophagitis. As reported previously (17) and confirmed in this study, this drug apparently increased the volume and $\mathrm{pH}$ of the gastric contents when administered i.g. at $300 \mathrm{mg} / \mathrm{kg}$. These results indicate that the mucosal protection is partly related to the buffering action of the drug. However, 10 or $30 \mathrm{mg} / \mathrm{kg}$ of sucralfate had no effect on the volume or $\mathrm{pH}$, but it significantly protected the esophagus. In addition, sucralfate administered i.d. at $300 \mathrm{mg} / \mathrm{kg}$ showed no effect on esophagitis and tended to increase the volume of the gastric contents. These results suggest that i.g. administered sucralfate acts through a direct protective mechanism, which was confirmed in the case of the protection against necrotizing agent-induced gastric lesions $(18,19)$. It is possible that both leminoprazole and sucralfate prevent esophagitis through similar mechanisms.

As expected, indomethacin markedly reduced the synthesis of prostaglandin $E_{2}$ in the esophagus for $4 \mathrm{hr}$. Since indomethacin pretreatment had no effect on the protective effect of leminoprazole, omeprazole or sucralfate (i.g.) against esophagitis, the participation of endogenous prostaglandins in the underlying mechanism could be ruled out.

We conclude that leminoprazole is a promising drug for the treatment of reflux esophagitis when administered via the oral route.

\section{Acknowledgments}

We wish to thank NJ Halewood for critical reviewing of this manuscript.

\section{REFERENCES}

1 Klinkenberg-Knol EC: Recent advances in the management of gastro-oesophageal reflux disease. Scand J Gastroenterol 26, Supp 188, $101-107$ (1991)

2 Thomson ABR: Medical treatment of gastroesophageal reflux disease: options and priorities. Hepatogastroenterology 39 , 14- 23 (1992)

3 Mohamed AH and Hunt RH: The rationale of acid suppression in the treatment of acid-related disease. Aliment Pharmacol Ther 8, Supp 1, 3- 10 (1994)

4 Inatomi N, Nagaya H, Takami K, Shino A and Satoh H: Effects of a proton pump inhibitor, AG-1749 (lansoprazole), on reflux esophagitis and experimental ulcers in rats. Jpn J Pharmacol 55, 437-451 (1991)

5 Goto $Y$ and Kishi S: Experimental model of acute esophagitis in the rat and comparison of effectiveness of antiulcer drugs including $\mathbf{H}_{2}$-antagonists and omeprazole. Jpn J Pharmacol 49, Supp 193P (1989)

6 Okabe S, Akimoto Y, Yamasaki S and Kuwahara K: Effects of a new benzimidazole derivative, $\mathrm{NC}-1300-\mathrm{O}-3$, on gastric secretion and gastroduodenal lesions in rats. Jpn J Pharmacol 55, $477-491$ (1991)

7 Okabe S, Takagi $\mathrm{K}$ and Inoue K: Effect of NC-1300-0-3 on healing of acetic acid-induced gastric ulcers in rats. Jpn $\mathrm{J}$ 
Pharmacol 62, 25-33 (1993)

8 Okabe S, Takeuchi K, Ohuchi T, Yamamoto $H$, Iwata $\mathrm{K}$ and Inoue K: Effects of NC-1300-O-3 and omeprazole on gastric acid secretion, bicarbonate secretion, gastric mucosal blood flow and transmucosal potential difference in rats. Ther Res 14, $373-389$ (1993)

9 Okabe $\mathrm{S}$, Inoue $\mathrm{K}$, Takagi $\mathrm{K}$, Iwata $\mathrm{K}$ and Yanagawa $\mathrm{T}$ : Comparative studies of antisecretory, antiulcer and mucosal protective effects of NC-1300-O-3 in rats with cimetidine and omeprazole. Ther Res 15, 349-366 (1994)

10 Nakamura K, Ozawa Y, Furuta Y and Miyazaki H; Effects of sodium polyacrylate (PANa) on acute esophagitis by gastric juice in rats. Jpn $\mathrm{J}$ Pharmacol 32, 445-456 (1982)

11 Lee $M$ and Feldman M: Nonessential role of leukotriens as mediators of acute gastric mucosal injury induced by aspirin in rats. Dig Dis Sci 37, 1282-1287 (1992)

12 Lee $\mathrm{M}$ and Feldman $\mathrm{M}$ : Age-related reductions in gastric mucosal prostaglandin levels increase susceptibility to aspirin-induced injury in rats. Gastroenterology 107, 1746-1750 (1994)

13 Mattsson $\mathrm{H}$, Andersson $\mathrm{K}$ and Larsson $\mathrm{H}$ : Omeprazole provides protection against experimentally induced gastric muco- sal lesions. Eur J Pharmacol 91, 111 - 114 (1983)

14 Konturek SJ, Brzozowski T and Radecki T: Protective action of omeprazole, a benzimidazole derivative, on gastric mucosal damage by aspirin and ethanol in rats. Digestion 27, 159- 164 (1983)

15 Elsborg $\mathrm{K}$ and Jorgensen F: Sucralfate versus cimetidine in reflux oesophagitis: A double-blind clinical study. Scand J Gastroenterol 26, 146-150 (1991)

16 Jorgensen $\mathbf{F}$ and Elsborg L: Sucralfate versus cimetidine in reflux esophagitis: The effect on oesophageal $\mathrm{pH}$ and motility. Scand J Gastroenterol 26, 263-268 (1991)

17 Ogihara $Y$ and Okabe S: Effect and mechanism of sucralfate on healing of acetic acid-induced gastric ulcers in rats. J Physiol Pharmacol 44, 109-118 (1993)

18 Hollander D, Tarnawski A, Krause WJ and Gergely H: Protective effect of sucralfate against alcohol-induced gastric mucosal injury in the rat. Gastroenterology 88, 366-374 (1985)

19 Morris GP, Keenan CM, MacNaughton WK, Wallace IL and Williamson TE: Protection of rat gastric mucosa by sucralfate. Am J Med 86, Supp 6A, 10-16 (1989) 